DOI: http://dx.doi.org/10.21123/bsj.2021.18.1(Suppl.).0812

\title{
Fixed Point Theorems in General Metric Space with an Application
}

\section{Hadeel Hussein Luaibi *}

Salwa Salman Abed

Department of Mathematics, College of Education for Pure Science Ibn AL-Haitham, University of Baghdad, Baghdad, Iraq

*Corresponding author: hadel_yamama@yahoo.com*, salwaalbundi@yahoo.com

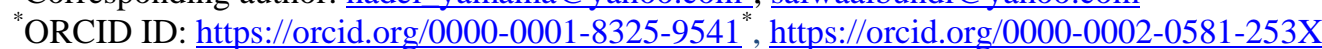

Received 31/7/2019, Accepted 26/10/2020, Published 30/3/2021

\begin{abstract}
This paper aims to prove an existence theorem for Voltera-type equation in a generalized G- metric space, called the $\vartheta_{v}$-metric space, where the fixed-point theorem in $\vartheta_{v^{-}}$metric space is discussed and its application. First, a new contraction of Hardy-Rogess type is presented and also then fixed point theorem is established for these contractions in the setup of $\vartheta_{v}$-metric spaces. As application, an existence result for Voltera integral equation is obtained.
\end{abstract}

Keywords: Contraction mappings , Fixed point, Integral inclusion, $\vartheta_{v}$ - metric space.

\section{Introduction}

The Banach's contraction concept is the most essentail outcome in non-linear analysis(1). Many researchers have generalized and utilized this principle, such as, (2-7). Various applications of Banach Principle have been presented. One of these applications is solving Voltera integral equations via fixed point theorems. As known, Banach, is the first to do this in his Ph.D. thesis(1) . For many other results in this branch see,(8-15). It is worth noting to citation a new Al-Bundy's results (16)about constructing a fractal in $\vartheta-$ metric spaces. In the current paper, Following previous researchers the authors achieve new results in this work.

Definition 1 (5) : Let $B$ be an non-empty set, a mapping $\vartheta_{v}: \mathrm{B}^{3} \rightarrow \mathcal{R}_{+}$is said tobe

$\left(\vartheta_{v}\right.$-metric ) for all $m_{1}, m_{2}, m_{3}, z \in B$ and $v \geq 1$ be a given real number satisfy the following
i. $\vartheta_{v}\left(m_{1}, m_{2}, m_{3}\right)=0$ if and only if $m_{1}=$ $m_{2}=m_{3}$
ii. $\vartheta_{v}\left(m_{2}, m_{1}, m_{3}\right)=\vartheta_{v}\left(m_{1}, m_{2}, m_{3}\right)=$ $\vartheta_{v}\left(m_{1}, m_{3}, m_{2}\right)$
iii. $\vartheta_{v}\left(m_{2}, m_{1}, m_{2}\right) \leqslant \vartheta_{v}\left(m_{1}, m_{2}, z\right)$ with $\mathrm{m}_{1} \neq \mathrm{m}_{2}$
iv. $\quad \vartheta_{v}\left(m_{2}, m_{1}, m_{2}\right)>0$ with $\mathrm{m}_{1} \neq \mathrm{m}_{2}$
v. $\quad \vartheta_{v}\left(m_{1}, m_{2}, m_{3}\right) \leq v\left(\vartheta_{v}\left(m_{1}, z, z\right)+\right.$ $\left.\vartheta_{v}\left(z, m_{2}, m_{3}\right)\right)$

Then $\left(B, \vartheta_{v}\right)$ is called a $\vartheta_{v}$-metric.
Proposition 2 (5):

$\begin{array}{ll}\text { 1. } & \vartheta_{v}\left(m_{1}, m_{2}, m_{3}\right) \leq v\left(\vartheta_{v}\left(m_{1}, z, m_{3}\right)+\right. \\ & \left.\vartheta_{v}\left(z, m_{2}, m_{3}\right)\right) \\ \text { 2. } & \vartheta_{v}\left(m_{1}, m_{1}, m_{2}\right) \leq 2 v \vartheta_{v}\left(m_{1}, m_{2}, m_{2}\right) .\end{array}$ Let $C(B)=$ the class of all non-empty closed sub-sets and $\mathrm{H}=$ Hausdorff $\vartheta_{a}$-metric

Now Hausdorff $\vartheta_{a}$-Metric is defined as follows (16)

Let $\mathrm{Q}, \mathrm{F}, \mathrm{X} \in B, \mathrm{H}: C(B) \times C(B) \rightarrow \mathcal{R}_{+}$such that

$\mathrm{H}(Q, F, X)$

$=\max \left\{\operatorname{Sup}_{x \in Q} \vartheta_{v}(x, \mathrm{~F}, \mathrm{X}), \sup _{x \in \mathrm{F}} \vartheta_{v}(x, Q, \mathrm{X}), \operatorname{Sup}_{x \in \mathrm{X}} \vartheta_{v}(x, \mathrm{~F}, Q)\right\}$

where,$\quad \vartheta_{v}(x, \mathrm{~F}, Q)=d_{\vartheta_{v}}(x, \mathrm{~F})+d_{\vartheta_{v}}(\mathrm{~F}, Q)+$ $d_{\vartheta_{v}}(x, Q)$,

$d_{\vartheta_{v}}(x, \mathrm{~F})=\inf \left\{d_{\vartheta_{v}}(x, f): f \in \mathrm{F}\right\}$.

Definition 3 (12): Let $\mathrm{F}=$ the family of all fiunctions, $\mathrm{W}: \mathcal{R}^{++} \rightarrow \mathcal{R}$ be function suchthat $\mathrm{W}_{1}$ :- Wis strictly nondecreasing, $d_{1}<d_{2} \rightarrow \mathrm{W}\left(\mathrm{d}_{1}\right)$ $<\mathrm{W}\left(\mathrm{d}_{2}\right), \forall d_{2}, d_{1} \in(0, \infty)$

$\mathrm{W}_{2}$ :- $\lim _{i \rightarrow \infty} \mathrm{W}\left(x_{i}\right)=-\infty \quad \Leftrightarrow \lim _{i \rightarrow \infty} x_{i}=0$, foreach sequence $\left\langle x_{i}\right\rangle$ of positive real numbers;

$\mathrm{W}_{3}$ :- If $\lim _{i \rightarrow \infty} x_{i}=0$, there exists $0<a<1$ such that $\lim _{i \rightarrow \infty}\left(x_{i}\right)^{a} \mathrm{~W}\left(x_{i}\right)=0$

$\mathrm{W}_{4}:-\forall$ sequence $\left\langle\beta_{i}\right\rangle \in \mathcal{R}^{+}$such tht $\epsilon+\mathrm{W}\left(v \beta_{i}\right) \leq$

$\mathrm{W}\left(v \beta_{i-1}\right)$. Some $\epsilon>0$ and $\forall \mathrm{i} \in \mathrm{N}$, so $\epsilon+\mathrm{W}\left(v^{i} \beta_{n}\right) \leq \mathrm{W}\left(v^{i-1} \beta_{i-1}\right)$.

Note (12):- For each $x>0$

- $\mathrm{W}(d)=\ln _{d}+d$ 
- $\mathrm{W}(d)=\ln _{d}$.

\section{Main Results:}

Initially, the following must be proved .

Lemma 4 : Let $\left(B, \vartheta_{v}\right)$ be $a \vartheta_{v}$-metric , and give any sequence in $\mathrm{B}$ (take $\left.\left\langle z_{i}\right\rangle\right), \exists t>0$ with $\mathrm{W} \in \mathrm{F}$ and $i \in N$

$t+\mathrm{W}\left[v \vartheta_{v}\left(\mathrm{z}_{i}, \mathrm{z}_{\mathrm{i}+1}, \mathrm{z}_{\mathrm{i}+2}\right)\right] \leq$

$\mathrm{W}\left[\vartheta_{v}\left(z_{i-1}, z_{\mathrm{i}}, z_{i+1}\right)\right]$

Then the sequence is Cauchy.

Proof - Suppose that $\vartheta_{v_{i}}=\vartheta_{v}\left(\mathrm{z}_{\mathrm{i}}, z_{i+1} ; z_{i+1}\right)$,

$\Rightarrow t+\mathrm{W}\left[\mathrm{v}^{\mathrm{i}} \vartheta_{\mathrm{v}_{\mathrm{i}}}\right] \leq \mathrm{W}\left[v^{\mathrm{i}-1} \vartheta_{v_{i-1}}\right]$, from (1) and $\mathrm{W}_{4}$.

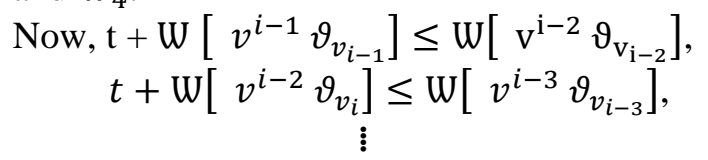

$\mathrm{W}\left[\mathrm{v}^{\mathrm{i}} \vartheta_{v_{i}}\right] \leq \mathrm{W}\left[v^{i-1} \vartheta_{v_{i-1}}\right]-t \leq$

$\mathrm{W}\left[v^{i-2} \vartheta_{v_{i-2}}\right]-2 t \quad \leq \mathrm{W}\left[v^{i-1} \vartheta_{v_{i-1}}\right] \leq \cdots \leq$

$\mathrm{W}\left[\vartheta_{v_{0}}\right]-i t \quad \ldots(2)$

$\Rightarrow \quad \mathrm{W}\left[v^{i} \vartheta_{v_{i}}\right] \leq \mathrm{W}\left[\vartheta_{v_{0}}\right]-i t \quad$ when

$\mathrm{i} \rightarrow \infty \Rightarrow \lim _{i \rightarrow \infty} \mathrm{W}\left(v^{i} \vartheta_{v_{i}}\right)=-\infty$.

From $W_{2} \Rightarrow \lim _{i \rightarrow \infty} v^{i} \vartheta_{v_{i}}=0$. And by condition $W_{3}$, there exsits $0<u<1$ such that $\lim _{i \rightarrow \infty}\left(v^{i} \vartheta_{v_{i}}\right)^{u} \mathrm{~W}\left(v^{i} \vartheta_{v_{i}}\right)=0$

By using (2)

$$
\begin{aligned}
\left(v^{i} \vartheta_{v_{i}}\right)^{u} \mathrm{~W}\left(v^{i} \vartheta_{v_{i}}\right) & \leq\left(v^{i} \vartheta_{v_{i}}\right)^{u} \mathrm{~W}\left(\vartheta_{v_{0}}\right)- \\
\left(v^{i} \vartheta_{v_{i}}\right)^{u} i t & \leq-\left(v^{i} \vartheta_{v_{i}}\right)^{u} i r \leq 0 \quad \ldots
\end{aligned}
$$

when $i \rightarrow \infty$, then

$$
\lim _{i \rightarrow \infty} i\left(v^{i} \vartheta_{v_{i}}\right)^{u}=0
$$

Then there exists $p \in N$ such that $i\left(v^{i} \vartheta_{v_{i}}\right)^{u} \leq$ 1 , for each $i \geq p$.

$$
\Rightarrow v^{i} \vartheta_{v_{i}} \leq \frac{1}{(i)^{\frac{1}{p}}}
$$

Let $i, f \in N$ since $p<i<f$.from (5) and definition (1-v), the lead to

$$
\begin{aligned}
& \vartheta_{v}\left(z_{i}, z_{f}, z_{f}\right) \leq \sum_{a=1}^{f-1} v^{a} \vartheta_{v_{a}} \leq \sum_{a=1}^{\infty} v^{a} \vartheta_{v_{a}} \leq \\
& \sum_{a=1}^{\infty} \frac{1}{(a)^{\frac{1}{p}}}<\epsilon
\end{aligned}
$$

That is $\left\langle z_{i}\right\rangle$ is Cauchy.

Definition 5 : Let B is $\vartheta_{v}$-metric, $S: B \rightarrow C(B)$ mapping with a function $\gamma: B \times B \rightarrow \mathrm{R}_{+}$is called $\left(\mathrm{W}, \vartheta_{v}\right.$ )-contraction if $\exists \mathrm{W} \in \mathrm{F}, t>0$ which that

$t+\mathrm{W}\left[v \mathrm{H}\left(S_{k}, S_{c}, S_{d}\right)\right] \leq \mathrm{W}[\underline{\Delta}(k, c, d)]$

with $\Delta\left(k_{\mathrm{r}}, c, d\right)=l_{1} \vartheta_{v}(k, c, \bar{d})+l_{2} \vartheta_{v}\left(k, S_{k}, S_{d}\right)+$ $l_{3} \vartheta_{v}\left(c, S_{c}, S_{d}\right)$ Since $\min \left\{\underline{\Delta}(k, c, d), \mathrm{H}\left(S_{k}, S_{c}, S_{d}\right)\right\}>0$. Satisfying the condition $l_{1}+2 v l_{2}+l_{3}=1, l_{3}$

not equal one and $l_{1}, l_{2}, l_{3} \geq 0$.

Theorem 6 : let $S: B \rightarrow C(B)$ be (W, $\left.\vartheta_{v}\right)$ contraction, $\mathrm{B}$ is complete $\vartheta_{v^{-}}$metric and $t>$ 0 such that the following

let $c_{0} \in S, \vartheta_{v}\left(c_{0}, c_{1}, c_{2}\right)$ since $c_{1} \in B_{c_{0}}, c_{2} \in S_{c_{1}}$

a. $S_{C}$ is closed for any sequence $\left\langle c_{i}\right\rangle$, then

Then $\mathrm{S}$ has a fixed point

$$
\left(c_{i}, c_{i+1}, c_{i+2}\right) \Rightarrow\left(c_{i}, \mathrm{c}, c\right) .
$$

Proof- by(a) , $c_{1} \in B_{c_{0}}, \vartheta_{v}\left(c_{0}, c_{1}, c_{2}\right)$ and $\exists c_{3} \in$ $B_{c_{2}}$

$$
v \vartheta_{v}\left(c_{1}, c_{2}, c_{3}\right) \leq v \mathrm{H}\left(S_{c_{0}}, S_{c_{1}}, S_{c_{2}}\right)
$$

Since $W_{1}, W\left(v \vartheta_{v}\left(c_{1}, c_{2}, c_{3}\right)\right) \leq$

$$
\mathrm{W}\left(v \mathrm{H}\left(S_{c_{0}}, S_{c_{1}}, S_{c_{2}}\right)\right)
$$

By $(6,7)$, then

$$
\begin{gathered}
t+\mathrm{W}\left(v \vartheta_{v}\left(c_{1}, c_{2}, c_{3}\right)\right) \leq \mathrm{t}+\mathrm{W}\left(v \mathrm{H}\left(S_{c_{0}}, S_{c_{1}}, S_{c_{2}}\right)\right) \\
\leq \mathrm{W}\left[l_{1} \vartheta_{v}\left(c_{0}, c_{1}, c_{2}\right)+\right. \\
\left.l_{2} \vartheta_{v}\left(c_{0}, c_{1}, c_{3}\right)+l_{3} \vartheta_{v}\left(c_{1}, c_{2}, c_{3}\right)\right]
\end{gathered}
$$

From Proposition (2)

$$
\leq \mathrm{W}\left[l_{1} \vartheta_{v}\left(c_{0}, c_{1}, c_{2}\right)+l_{2}\left(v \vartheta_{v}\left(c_{0}, c_{1}, c_{2}\right)+\right.\right.
$$

$\left.\left.v \vartheta_{v}\left(c_{1}, c_{2}, c_{3}\right)\right)+l_{3} \vartheta_{v}\left(c_{1}, c_{2}, c_{3}\right)\right]$

where $l_{1}+2 l_{2}+l_{3}=1$ and $W_{1}$,

$$
\begin{aligned}
& \Rightarrow \quad v \vartheta_{v}\left(c_{1}, c_{2}, c_{3}\right)-v l_{2} \vartheta_{v}\left(c_{1}, c_{2}, c_{3}\right)- \\
& l_{3} \vartheta_{v}\left(c_{1}, c_{2}, c_{3}\right) \\
& l_{1}\left(c_{0}, c_{1}, c_{2}\right)+v l_{2} \vartheta_{v}\left(c_{0}, c_{1}, c_{2}\right) \\
& \left(1-v l_{2}-l_{3}\right) \vartheta_{v}\left(c_{1}, c_{2}, c_{3}\right) \leq \\
& \vartheta_{v}\left(c_{0}, c_{1}, c_{2}\right) . \\
& \quad \Rightarrow \mathrm{t}+\mathrm{W}\left(v \vartheta_{v}\left(c_{1}, c_{2}, c_{3}\right)\right) \leq \mathrm{W}\left[\vartheta_{v}\left(c_{0}, c_{1}, c_{2}\right)\right]
\end{aligned}
$$

By continuous in this away, leads to

$\mathrm{r}+\mathrm{W}\left(v \vartheta_{v}\left(c_{i}, c_{i+1}, c_{i+2}\right)\right)$

$\leq \mathrm{W}\left[\vartheta_{v}\left(\mathrm{c}_{\mathrm{i}-1}, c_{i}, \mathrm{c}_{i+1}\right)\right], \forall i \in N$

From lemma ( 4), then $\left\langle c_{i}\right\rangle$ is cauchy sequence.

Since B is complete $\exists c \in B \Rightarrow c_{i} \rightarrow c$.

Using the condition (b), that is $\vartheta_{v}\left(S_{c}, c, c\right)=0 \Rightarrow$ $c \in S_{c}$. If converse that $c \notin S_{c}$, then $\exists m \in N$ such that $\vartheta_{v}\left(c_{i}, c, S_{c}\right)>0 \forall m<i$.

Then

$$
\begin{aligned}
& \vartheta_{v}\left(c, S_{c}, S_{c}\right) \leq v \vartheta_{v}\left(c, c_{i+1}, c_{i+1}\right) \\
&+v \vartheta_{v}\left(c_{i+1}, S_{c}, S_{c}\right) \\
& \leq v \vartheta_{v}\left(c, c_{i+1}, c_{i+1}\right)+\mathrm{H}\left(S_{c_{i}}, S_{c}, S_{c}\right) \\
& \leq v \vartheta_{v}\left(c, c_{i+1}, c_{i+1}\right)+l_{1} \vartheta_{v}\left(c_{i}, c, c\right)+ \\
& l_{2} \vartheta_{v}\left(c_{i}, c_{i+1}, S_{c}\right)+l_{3} \vartheta_{v}\left(c, S_{c}, S_{c}\right) \\
& \leq l_{2} \vartheta_{v}\left(c, c, S_{c}\right)+l_{3} \vartheta_{v}\left(c, S_{c}, S_{c}\right) \\
& \leq 2 v l_{2} \vartheta_{v}\left(c, S_{c}, S_{c}\right)+l_{3} \vartheta_{v}\left(c, S_{c}, S_{c}\right), \text { by }
\end{aligned}
$$

Proposition (2)

$\Rightarrow \quad \vartheta_{v}\left(c, S_{c}, S_{c}\right) \leq\left(2 v l_{2}+l_{3}\right) \vartheta_{v}\left(c, S_{c}, S_{c}\right)<$ $\vartheta_{v}\left(c, S_{c}, S_{c}\right)$. This is contraction. 
Collaray 7 : Let $S: B \rightarrow C(B)$ be $\left(\mathrm{W}, \vartheta_{v}\right)$ contraction, B is complete $\vartheta_{v^{-}}$metric , $v>0$ and satisfying all conditions with

$$
\begin{gathered}
v \mathrm{H}\left(S_{k}, S_{c}, S_{d}\right) / \underline{\Delta}(k, c, d) e^{v \mathrm{H}\left(S_{k}, S_{c}, S_{d}\right)-\underline{\Delta}(k, c, d)} \\
\leq e^{-t}
\end{gathered}
$$

Then $\mathrm{S}$ has a fixedpoint.

Example 8: Let $\mathrm{B}=\{0,1,2,3\}, \vartheta_{v}(a, b, b)=$ $[2|a-b|]^{2}$ is $\vartheta_{v}$-metric for each $\mathrm{a}, \mathrm{b} \in B$ since $v=2$. Let $f: B \rightarrow C(B)$, define

$$
f_{a}=\left\{\begin{array}{c}
\{0,1\} \quad \text { if } a=0,1 \\
\{2,3\} \quad \text { if } a>1
\end{array} .\right.
$$

Solution:- $\forall a, b>1$ and $a \neq b$, suppose $l_{1}=$ 1 , and $l_{2}, l_{3}$ is equal zero .

That is, $\min \left\{\vartheta_{v}(a, b, b), \mathrm{H}\left(f_{\mathrm{a}}, f_{b}, f_{b}\right)\right\}>0$. Since $\vartheta_{v}(a, b, b)=4, \mathrm{H}\left(f_{\mathrm{a}}, f_{b}, f_{b}\right)=4, t=\frac{1}{2}$ and from corollary (7).

$$
\Rightarrow \quad \mathrm{e}^{0} \leq \mathrm{e}^{-\frac{1}{2}}
$$

with $\mathrm{W}_{a}=\ln a+a, \forall a \in \mathrm{R}^{+}$.

Then satisfies all conditions theorem 6), $\in f_{a}$. D

\section{Application}

In this section the gotten outcomes were used to attain the existence of solutions for a specific Fredholmtype integral consolidation. The application is motivated by(12)

Express the Fredholm-type as follows

$\mathrm{y}(\mathrm{u}) \in \int_{a}^{u}$ ? $(u, \mathrm{x}, y(x))+\alpha(u) . \mathrm{u} \in[\mathrm{a}, \mathrm{c}]$

Let $G_{C V}(R)=$ the family of non-empty convex and compact subset $\mathrm{R}$, ?: $[a, c]^{2} \times R \rightarrow G_{C V}$, the operator ${ }_{y}:=0(\mathrm{u}, x, y(x))$ is continuous since $\alpha:[a, c] \rightarrow R$ is continuous for all $y \in C[a, c]$.

Now, B is complete $\vartheta_{v}-$ metric by considering $\vartheta_{v}\left(x_{1}, x_{2}, x_{3}\right)=\sup _{\mathrm{u} \in[\mathrm{a}, \mathrm{c}]} \quad\left[\left|x_{1}-x_{2}\right|+\left|x_{2}-x_{3}\right|+\right.$ $\left.\left|x_{3}-x_{1}\right|\right]^{2}$, for $v=2$.

Theorem 9: Let $\delta=C([a, c], R)$ and let the setvalued operator $f: \delta \rightarrow C(\delta)$ defined by

$$
f_{\mathrm{y}(\mathrm{u})}\left\{\begin{array}{c}
\mathrm{s} \in \delta: \mathrm{s} \in \int_{a}^{u} \mathrm{a}(\mathrm{u}, \mathrm{x}, \mathrm{y}(\mathrm{x}))+K(u), \\
u \in[a, c]
\end{array}\right\} .
$$

Since $K(u)$ is continuos

And assume the following:

1- There exists $h:[a, c] \rightarrow R$ is a continuous function such that $\mathrm{H}\left(\mathrm{g}\left(u, x, b_{1}(x)\right)\right.$, ? $\left(u, x, b_{2}(x)\right)$, ? $\left.\left(u, x, b_{3}(x)\right)\right)$ $\leq h(x)\left[\left|\mathrm{b}_{1}(x)-b_{2}(x)\right|+\left|b_{2}(x)-b_{3}(x)\right|\right.$

$$
\left.+\left|b_{3}(x)-b_{1}(\mathrm{x})\right|\right]
$$

2- For each $\mathrm{b}_{1}, b_{2}, b_{3} \in B, \exists \mathrm{t}>0$.let that

$$
\int_{a}^{u} h(x) \leq \sqrt{e^{-t}}
$$

Then the operator has a fixed point.

Proof - the operator $f$ should be satisfied all hypothesis of Theorem(6). Initially, the equation (6) must be inspected. Let $b_{1}, b_{2}, b_{3} \in$ Bsuch that $s \in$ $f_{b_{1}}$.

$\Rightarrow \quad ?_{b_{1}}(u, x) \in$ ? $_{b_{1}}(u, x)$, such that $s_{u}=$ $\int_{a}^{u}{ }_{b_{1}}(u, x) d x+K(u)$ for $u \in[a, c]$.

However, put $?_{b_{2}}(u, x) \in ?_{b_{2}}(u, x)=?_{b_{3}}(\mathrm{u}, \mathrm{x})$ ,by condition (i) makes sure that $\exists y(u, x) \in$ ]$_{b_{2}}(\mathrm{u}, \mathrm{x})$ such that

$\left|{ }_{b_{1}}(u, \mathrm{x})-\mathrm{y}(u, x)\right|+\left|y(u, x)-\mathrm{Q}_{b_{1}}(u, x)\right| \leq$ $h(x)\left[\left|b_{1}(\mathrm{x})-b_{2}(\mathrm{x})\right|+\right.$

$\left.\left.\mid b_{2} x\right)-b_{1}(\mathrm{x}) \mid\right]$ forall $x \in[\mathrm{a}, \mathrm{c}]$

Let us take into consideration the multivalued operator $T$ defined by

$T_{(u, x)}$

$={ }_{b_{2}}(u, \mathrm{x})$

$\cap\left\{\begin{array}{c}q \in R: \mid]_{b_{2}}(u, \mathrm{x})-\mathrm{q}|+| \mathrm{q}-\mathrm{g}_{b_{2}}(u, x) \mid \\ \leq h(x)\left[\left|\mathrm{b}_{1} \cdot(x)-\mathrm{b}_{2}(x)\right|+\left|b_{2}(x)-b_{1}(\mathrm{x})\right|\right]\end{array}\right\}$.

$$
f_{u}=\int_{a}^{u}{ }_{b_{b_{2}}}(\mathrm{u}, \mathrm{x}) d x+h(x) \text { since }{ }_{b_{2}}(u, x)
$$

$$
\in ?_{b_{2}}(u, x)
$$

Then

$$
\begin{aligned}
& {\left[\left|s_{u}-f_{u}\right|+\left|f_{u}-s_{u}\right|\right]^{2}} \\
& \leq\left[\int _ { a } ^ { u } \left(\left|\vartheta_{b_{1}}(u, x)-\vartheta_{b_{2}}(u, x)\right|\right.\right. \\
& \left.\left.+\left|?_{b_{2}}(u, x)-?_{b_{1}}(u, x)\right|\right) d x\right]^{2} \\
& \leq\left[\int _ { \boldsymbol { a } } ^ { u } h ( x ) \left(\left|b_{1}(x)-b_{2}(x)\right|\right.\right. \\
& \left.\left.+\left|\mathrm{b}_{2}(x)-b_{1} \mathrm{x}\right|\right) d x\right]^{2} \\
& \leq\left[\sqrt{\text { sup }_{x \in[a, c]}\left(\left|b_{1}(x)-b_{2}(x)\right|+\left|b_{2}(\mathrm{x})-b_{1}(x)\right|\right)^{2}} \int_{a}^{u} h(x) d x\right]^{2} \\
& \leq e^{-t} \vartheta_{v}\left(b_{1}, b_{2}, b_{2}\right) \Rightarrow \vartheta_{v}(s, f, f) \leq \\
& e^{-t} \vartheta_{v}\left(b_{1}, b_{2}, b_{2}\right)
\end{aligned}
$$

By simply swapping the role of $b_{1} \& b_{2}$, and applied natural logarithm, the lead to

$$
r+\mathrm{W}\left[\mathrm{H}\left(f_{b_{1}}, f_{b_{2}}, f_{b_{2}}\right)\right] \leq \mathrm{W}\left[\vartheta_{v}\left(b_{1}, b_{2}, b_{2}\right)\right]
$$

Since $\mathrm{W}(d)=\ln d$ and $f$ is $\left[\left(\mathrm{W}, \vartheta_{v}\right)\right.$-contraction with $l_{1}=1, l_{2}=l_{3}=0$.After that all the condition for theorem are satisfied (6). Hence the operator $f$ has afixed point. 


\section{Conclusion:}

The effect of this study indicates that the integral Volterra equations satisfying the contractive condition have a fixed point. The solution of an integral equation by the fixed point method is approximated by showing some suitable conditions guarantee the convergence of the method.

\section{Authors' declaration:}

- Conflicts of Interest: None.

- Ethical Clearance: The project was approved by the local ethical committee in University of Baghdad.

\section{References:}

1. Zeidler E .Nonlinear Functional Analysis and its Applications: Part 1: Fixed-Point Theorms. Springer 1985;(1).

2. Czerwik $\mathrm{S}$. On the stability of the quadraticmapping in normed spaces. in Abhandlungen aus dem Mathematischen Seminar der Universität Hamburg. 1992. Springer.

3. Abed S S . Approximating Fixed Points of The General Asymptotic Set Valued Mappings J. of Adva. in Math. 2020;18:52-59.

4. Mustafa Z . A New Structure for Genralized Metric Spaces: With Applications to Fixed PointTheory. Univ. of Newcastle .2005 .

5. Aghajani A, Abbas M, Roshan JR. Common fixed point of generalized weak contractive mappings in partially ordered Gb-metric spaces. Filomat. 2014 Jan 1;28(6):1087-101.

6. Singh T C, Singh Y R. A Comparative Study of Relationship Among Various Type of Spaces. Int. J. Appl. Math. 2015; 25: 29-36.
7. Jaradat M M, Mustafa Z, Khan S U, Arshad M, Ahmad J.Some Fixed Point Results on G-metric and Gb-Metric Spaces. Demonstratio Math. 2017;50(1):190-207.

8. Abed S S . Fixed Point Principles in General b-Metric Spaces and b-Menger Probabilistic spaces. J. of AlQadisiyah comput. Sci. Math. . 2018; 10(2): 42-53.

9. Aydi H , Jellali M , Karapınar E. CommonFixed points for Generalized \$\$lalpha \$ \$-implicit Contractions in Partial metric Spaces: consequences and application. Revista de la Real Academia de Ciencias Exactas, Físicas y Naturales. Serie A. Matemáticas.2015; 109(2): 367-384.

10. Abed S S, Luaibi H H. On Common FixedPoints in Generalized Menger Spaces. Inter. J. of Appl. Math. Reserch .2016;5(4): 197.

11. Cosentino M, Jleli M, Samet B, Vetro C. Solvability of Integrodifferential Problems via Fixed Point Theory in b-metric Spaces. Fixed Point Theory and Appl. . 2015; 2015(1): 70.

12. Sîntămărian A. Integral inclusions of Fredholm type relative to multivalued $\varphi$-contractions. Seminar on Fixed Point Theory Cluj-Napoca. 2002.

13.Aydi H, Felhi A, Sahmim S. Related fixed point results for cyclic contractions on $G$-metric spaces and application. Filomat. 2017; 31(3):853-869.

14. Abed SS, Hasan ZM. Convergence Comparison of two Schemes for Common Fixed Points with an Application. Ibn AL-Haitham J. For Pure and Appl. Sci. . 2019 May 20;32(2):81-92.

15. Aydi H, Felhi A , Sahmim S. Related fixed Point Results for Cyclic Contractions on Filomat.2017; 31(3): 853-869.

16. Albundi Sh S. Iterated function system in $\vartheta$-metric spaces. accepted in Bole. da Soci. Para. de Matem., 2020.

\section{مبرهنات النقطة الصامدة في فضاء متري معمم مع تطبيق

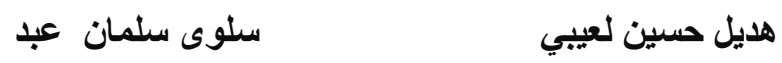 \\ قسم الرياضيات، كليةالتربية للعلوم الصرفة، ابن الهيثم ، جامعة بغداد، بغداد، العراق}

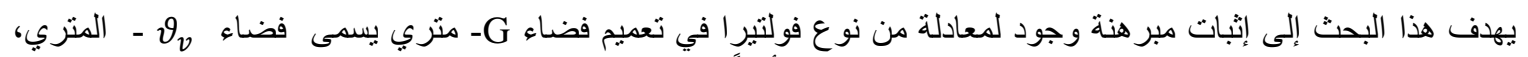

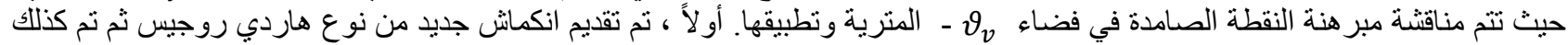
إنشاء مبر هنة النقطة الصامدة لهذه الانكماثنات في حالة فضاء

الكلمات المفتاحية: تطبيقات انكماثية ، النقطة الصامدة، فضاء v 